\title{
O TEMPO E O ESPAÇO DO BRINCAR NA EDUCAÇÃO INFANTIL
}

\author{
Susana Angelin Furlan', José Milton de Lima², Márcia Regina Canhoto de Lima ${ }^{3}$
}

Universidade Estadual Paulista - UNESP, ${ }^{(1)}$ Mestrado em Educação, ${ }^{(2)}$ Departamento de Educação, ${ }^{(3)}$ Departamento de Educação Física, Presidente Prudente- SP. E-mail: susanaangelin20@gmail.com. Agência de Fomento: Conselho Nacional de Desenvolvimento Cientifico e Tecnológico- CNPq

\section{RESUMO}

Esta pesquisa trata-se de um recorte de uma iniciação cientifica que tem como foco o espaço e o tempo das brincadeiras com as crianças na pré-escolar. A pesquisa contou com a parceria de oito salas de Educação Infantil de uma Instituição Municipal, no interior de São Paulo e a participação de oito educadoras e de aproximadamente 200 crianças de 3 a 5 anos. $O$ referencial teórico predominante neste estudo é o da Sociologia da Infância juntamente com os autores que dissertam sobre a temática do tempo e o espaço das brincadeiras dentro da Educação Infantil. A metodologia utilizada foi qualitativa, caracterizada como Pesquisa do tipo etnográfica. Os resultados alcançados revelam que a ludicidade é uma expressão ímpar da criança dentro do espaço escolar, mas que vem sendo suprimida pela lógica capitalista de mercado, que prioriza os conteúdos relacionados aos saberes linguísticos e matemáticos, revelando-nos um adiantamento dos conteúdos escolares.

Palavras-chave: Criança; Educação Infantil; Brincadeiras; Espaço; Tempo.

\section{THE TIME AND THE SPACE OF PLAY IN EARLY CHILDHOOD EDUCATION}

\section{ABSTRACT}

This research it is a clipping of a scientific initiation that focuses on space and time play with children in preschool. The research had the partnership of eight early childhood rooms of a Municipal Institution, in São Paulo and the participation of eight teachers and approximately 200 children from 3 to 5 years. The predominant theoretical in this study is the sociology of childhood along with the authors that descant on the theme of time and space of games inside of early childhood education. The methodology used was qualitative, characterized as ethnographic type lookup. The results obtained show that the playfulness is a unique expression of the child within the school space, but which has been suppressed by the capitalist market logic, which prioritizes the content related to the linguistic and mathematical knowledge, revealing us an advance of school content.

Keywords: Child; Early Childhood Education; Jokes; Space; Time.

\section{INTRODUÇÃO}

A Educação Infantil deve ser um lugar onde por excelência deva proporcionar para a criança seu desenvolvimento integral, primando pela socialização secundária, pois é o local onde a criança com parceiros da mesma idade tem a sua socialização firmada, depois da família.

Desta forma a Educação Infantil, caracteriza-se como o primeiro contato da criança com a escola, o que a posiciona em um patamar de grande importância. Com tais ditos, compreendemos que os saberes que são compartilhados e vivenciados em suas dependências repercutirão por todo o desenvolvimento dos infantes.

Sendo assim, do ponto de vista legal temos que:

A Educação Infantil é a primeira etapa da Educação Básica e tem como finalidade o desenvolvimento integral da criança de zero a cinco anos de idade em seus aspectos físico, afetivo, intelectual, linguístico e social, complementando a 
ação da família e da comunidade" (BRASIL. Ministério da Educação, 2009, p. 03).

As crianças não nascem sabendo brincar, não é algo inerente a elas, mas através das vivências e experiências com os pais, vizinhos, colegas, irmãos mais velhos, entre outros, ou seja, do meio social elas vão construindo seu repertório e tendo acesso ao mundo por meio da ludicidade e suas representações.

Desta forma as crianças não são tábulas rasas ou recipientes que devem ser preenchidos com a cultura adulta, mas vão através da reprodução interpretativa (CORSARO, 2011) aprendendo o mundo da sua maneira e o transformando através das suas brincadeiras, não sendo uma simples reprodução, mas uma apreensão do mundo a sua maneira, modificando-o e criando, a partir de suas experiências.

Entendemos juntamente com a Sociologia da Infância, que faz parte do nosso arcabouço teórico, que a criança não é um devir, ou seja, não pode ser vista na perspectiva de um adulto que será, mas sim um sujeito de direito, que pode transformar a sua realidade, de uma categoria social heterogênea do tipo geracional.

A Sociologia da Infância entende que a criança tem culturas, nomeada como Culturas da Infância, que possui eixos estruturados, a saber: Fantasia do Real (linguagem imaginativa da criança), Interactividade (a relação das crianças com seus pares), Reiteração (o tempo da criança, que é diferenciado e recursivo) e a Ludicidade, que é a brincadeira como forma de expressão e desenvolvimento da criança, eixo qual destacaremos ao longo da pesquisa.

Sendo assim, destacaremos nesse artigo como objetivos entender qual o tempo e o espaço que a brincadeira ocupa dentro da instituição de Educação Infantil pesquisada, além de buscar compreender como os professores lidam com essa ludicidade tão importante nessa fase da vida.

\section{METODOLOGIA}

Em busca de elucidar esses objetivos, utilizamos da metodologia qualitativa, que não tem uma dimensão quantificável, mas sim interpretativa. Segundo Richardson (1989, p.6) uma metodologia qualitativa:
[...] pode descrever a

complexidade de

determinado problema, analisar a interação de certas variáveis, compreender e classificar processos dinâmicos vividos por grupos sociais, contribuir no processo de mudança de determinado grupo e possibilitar, em maior nível de profundidade, o entendimento das particularidades do comportamento dos indivíduos.

Utilizamos da pesquisa do tipo etnográfica, segundo Ludke e André (1986, p.14) "a etnografia é a descrição de um sistema de significados culturais de um determinado grupo".

A pesquisa em questão recebe essa característica porque na área educacional há alguns requisitos adaptáveis, ou seja, que não necessitam ser rigidamente seguidos, como, por exemplo, uma longa permanência do pesquisador no campo de pesquisa, o contato com outras culturas e o uso de muitas categorias sociais de análise, assim o que se faz é uma adaptação do estudo etnográfico (ANDRÉ, 2003).

O grupo pesquisado é formado por aproximadamente 200 crianças de 3 a 5 anos e 08 educadoras de uma instituição de Educação Infantil localizada no município no Estado de São Paulo. As observações/participação ocorrem uma vez na semana, no período da manhã e da tarde.

Como afirma Agostinho (2007), esse tipo de pesquisa deve ultrapassar o "déficit" de racionalidade e competência das crianças, e serem consideradas enquanto sujeitos do processo de pesquisa, onde a sua voz e ação, são perceptíveis de serem analisadas a partir delas mesmas.

Como abordagem metodológica, optamos, por ser um observador participante. Como afirma Ludke e André (1986) para se comportar como tal:

(...) o pesquisador deve tentar encontrar meios para compreender o significado manifesto e latente dos comportamentos dos indivíduos, ao mesmo tempo que procura manter sua 
visão objetiva do fenômeno. O pesquisador deve exercer - papel subjetivo de participante e o papel objetivo de observador, colocando-se numa posição impar para compreender e explicar o comportamento humano. (LUDKE E ANDRÉ, 1986, p. 15).

A pesquisa utilizou-se as técnicas de observação entrevistas, questionários, levantamento bibliográfico e diário de campo. Tal escolha se justifica, pois estas técnicas auxiliam no levantamento de dados que permitem desvelar a complexidade do problema (RICHARDSON, 1989).

Ademais, a base teórica, conta com as contribuições, através da discussão de materiais sobre a Sociologia da infância, que ocorrem quinzenalmente, no CEPELIJ, Centro de Estudos e Pesquisa em Educação, Ludicidade, Infância e Juventude, que dispões também dos aportes de mestrandos, doutorando e docentes da UNESP.

Visto que esta pesquisa é feita com crianças, necessário se faz citar o número do comitê de ética: 13424213800005402 .

\section{RESULTADOS}

Em busca dos nossos objetivos, além das observações, fotografias e conversas com os sujeitos de pesquisa, realizamos uma entrevista com as educadoras da instituição escolar. Durante a entrevista, perguntamos sobre como valorizam o brincar na Educação Infantil. Elas Disseram que sempre deixam o tempo que sobra para brincar, destaque para a fala de Aparecida, que praticamente representa a de todas:

É complicado o tempo do brincar, porque na escola temos duas apostilas mais o conteúdos, mais as outras aulas que não estamos com as crianças, como artes, educação física e ai o brincar fica bem restrito, pro final da aula quando eles já fizeram todas as atividades e sobrou lá uns 20 minutos, uns 30 minutos que eu vi que não tem mais como dar outra atividade, ai deixo eles brincarem. E esses conteúdos são livres, usando os brinquedos que tem, fazendo de faz de conta, só tenho cuidado de não se machucarem, de não quebrarem brinquedos. (Aparecida-professora Infantil II, Diário de campo)

Infelizmente, a ludicidade, um dos eixos estruturadores das culturas da infância é desvalorizada e já na Educação Infantil os saberes linguísticos e matemáticos são sobrepostos frente a outros elementos essenciais de suas culturas, muito pela burocracia imposta pelo sistema apostilado, ou por práticas que não atendem mais aos pequenos.

O brincar é fundamental na infância, faz parte do seu processo de desenvolvimento e colabora com a atenção, desenvolvimento da imaginação, socialização, cognição, entre outros fatores. Sendo o que a criança faz de mais sério nesse período, mas por tentar sempre alfabetizar antes do previsto, antes de ter outras habilidades e vivências, sucateamos alguns elementos fundamentais como a partilha com seus pares, a brincadeira, e os elementos culturais que a criança tem acesso fora da escola.

Para melhor ilustrar ainda a necessidade das crianças brincarem, transcreveremos a fala de um aluno, Matheus, do infantil II, que dizia a um colega: "Eu gostava tanto da creche, quando eu era pequeno, eu ficava lá, e brincava muito, tinha gira-gira, escorrega, areia"- Matheus, infantil II (Diário de campo)

Matheus nos revela uma nostalgia de quando era pequeno, mas se faz necessário dizer que essa é a fala de um menino de 5 anos, que não viveu ainda toda a sua infância e pelas preocupações com o conteúdo, tem o seu brincar deixado de lado, para dar conta de algo que poderia esperar para que a infância fosse vivida plenamente.

Consideramos primordial o papel do educador como mediador dos aspectos culturais que a criança trás para dentro da escola, como a valorização do brincar. Durante as nossas observações, vimos que há algumas professoras ainda não dão atenção a ludicidade. Porém, vivenciamos momentos com duas professoras, em especial, que promoviam uma excelência no brincar, enriquecendo a atividade lúdica até mesmo com a sua participação. 

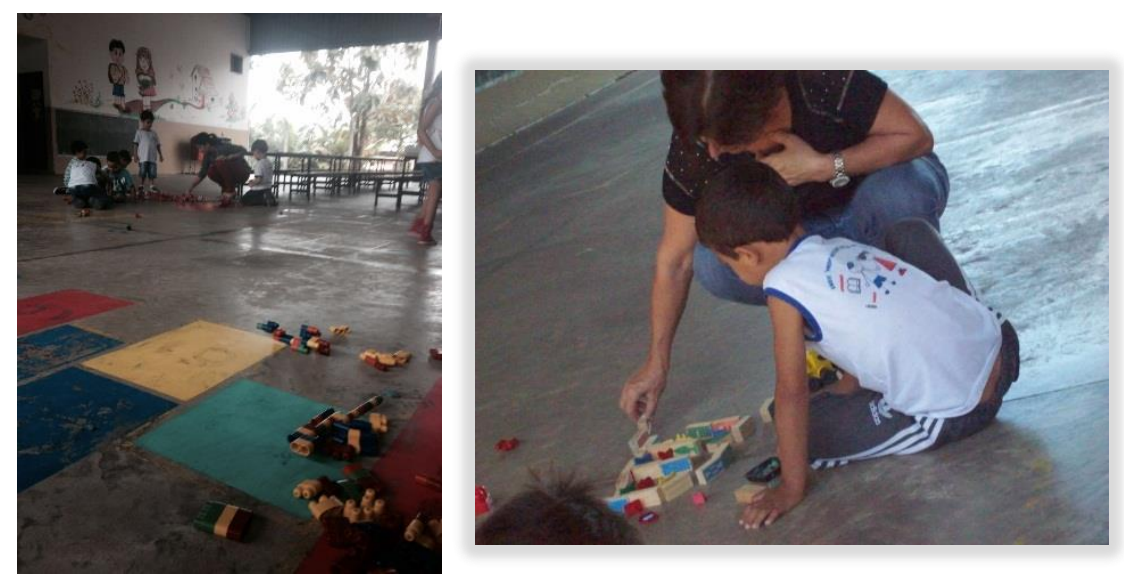

Figura 1 e 2. Professoras brincando com as crianças

Em entrevista com a gestora da instituição ela nos falou um pouco sobre o brincar e como ele se dava dentro da escola.

"A atividade lúdica, a brincadeira, encontra maior espaço, ela contribui no desenvolvimento infantil, facilitando a construção da autonomia, cumprimento das regras, limites e respeito aos colegas"- Fátima, gestora da instituição.

A gestora reconhece a importância do brincar, mas pelos conteúdos que as crianças têm que dar conta, a maioria das professoras passa esse aspecto para segundo plano, como já foi relatado nos trechos das entrevistas das professoras.

As crianças por diversos momentos conclamam por mais tempo para a manifestação de sua cultura lúdica dentro da escola. Assim, a fim de viver esse aspecto de sua cultura, as crianças buscam a clandestinidade.

Observamos isso em muitos momentos dentro da escola, quando os alunos eram repreendidos pelos adultos mesmo quando brincavam em situações propícias, como na hora do intervalo ou na chegada e na saída da instituição. Os inspetores e outros diziam que eles deveriam ficar quietos e só esperar, sem levar em conta que aquele era o único momento que eles estavam com seus pares e podiam brincar sem nenhuma restrição.

É preciso valorizar a escola como o encontro dos pares, como lugar de viver essa cultura da brincadeira, para que, tendo espaço e tempo para isso, com o cuidado do fornecimento e provisão dos adultos eles possam aumentar seu arcabouço lúdico, experenciar diversos movimentos e deixar com que as suas faculdades como memória, imaginação, criatividade, entre outras, sejam utilizadas e aperfeiçoadas.

As crianças, muitas vezes, não conseguem reproduzir e aumentar a sua cultura lúdica fora da escola porque se veem sem pares para brincar. Devido ao menor número de filhos por casal, como pudemos constatar através de pesquisas neste campo, as crianças tem poucos primos e irmãos com quem brincar; deste modo, a ampliação de sua cultura lúdica por meio do contato com os pares fica restrita aos momentos que se encontram na escola.

A partir desta situação exploramos uma conversa que foi observada durante uma brincadeira das crianças e que faz jus a circunstância acima descrita:

- Sabe Prô, eu não tenho ninguém pra brincar!

- Como não? Você tem eu.

- Mas eu quis dizer na minha casa!

-Ah...eu nunca fui na sua casa! (Diário de campo)

Percebemos que as crianças não tem o costume de ir à casa uns dos outros, muitas vezes pela distância ou falta de proximidade entre as crianças. Deste modo, o que se faz necessário entender é que sem os momentos com outras crianças, só com os adultos, a ludicidade e o conhecimento do mundo por essa via que não com a cultura de pares, fica comprometida.

Como também podemos perceber na fala de uma menina. Quando perguntada com quem ela brinca, responde: "Brincar mesmo eu brinco 
com os meus amigos na escola, em casa eu brinco sozinha, só ás vezes eu quero brincar com a minha mãe".

O tempo do brincar é aquele que as crianças encontram longe dos olhares atentos dos adultos, na entrada, recreio e intervalo; o espaço é aquele proporcionado pela escola, um pequeno pátio. E desta forma, as crianças vão vivendo quase que clandestinamente a sua infância, procurando a melhor maneira de aproveitar-se da companhia dos colegas e aproveitando como podem da ludicidade para entender o mundo.

\section{DISCUSSÃO}

Buscou-se desvelar por meio da construção da base teórica sobre cultura lúdica como as crianças interagem por meio da brincadeira, qual o espaço e o tempo do brincar.

Segundo as Diretrizes Curriculares Nacionais para Educação Infantil, a brincadeira é uma maneira de oportunizar o movimento para que a criança crie um maior domínio do seu corpo, contribuindo para a promoção do conhecimento de si e do mundo com experiências sensoriais, expressivas, corporais que possibilitem movimentação ampla, expressão de ritmos, respeito e desejos das crianças.

Não se sabe a real origem de diversos jogos, porém sabemos que a sua transmissão se dá de forma oral. Ainda as autoras destacam em consonância com Sarmento (2002), que mesmo as crianças que vivem em situação precária, exercem as suas capacidades humanas de apropriação de cultura através do brincar.

Como argumentam Pontes e Magalhães (2002, p. 214)

No sentido sociológico do termo, pode-se dizer que as brincadeiras tradicionais infantis configuram-se como verdadeiras instituições, pois são estruturas decorrentes de necessidades sociais básicas, com caráter de relativa permanência e identificáveis pelo valor de seus códigos de conduta.

Segundo Friedmann (1990 apud PONTES; MAGALHÃES, 2002) os jogos tradicionais infantis caracterizam uma cultura local. Destaca-se que ocorre uma supressão de regras, mudança de nomes ou outra variação que caracteriza uma determinada localidade. Como exemplo, podemos citar o jogo conhecido na região de Presidente Prudente como "Betts", e na região de Piracicaba como "Taco", possuindo as mesmas regras e determinando uma cultura local.

Para Brougère (2000) o jogo é uma representação dos aspectos da sociedade, associando a dimensão simbólica a funções específicas do convívio e desenvolvimento humano. São palavras-chave para entender os jogos tradicionais, como afirma Kishimoto (1993): conservação, mudança e universalidade.

Destacamos a importância dos jogos, com a pintura representativa de 1560 , chamada "Jogos Infantis", de autoria de Pieter Brueghel, onde conseguimos identificar cerca de 250 pessoas brincando de 84 jogos. Alguns conhecidos até hoje como "Cabra-cega"1, e "Maria cadeira" 2 .

\footnotetext{
1 Cabra-cega: um dos participantes de olhos vendados procura, agarrar e adivinhar os outros. Aquele que for pego, passará a ficar com os olhos vendados. Atualmente é um jogo infantil, mas na Idade média foi um passatempo palaciano.

${ }^{2}$ Maria cadeira: Duas crianças traçam os braços para formar uma cadeira humana, usada para lançar um dos companheiros após o canto de um versinho: "onde vai Maria Cadeira?/Vai a casa do Capitão,/ O Capitão não está em casa,/Joga Maria Cadeira no chão/ Joga Maria Cadeira no chão..."
} 


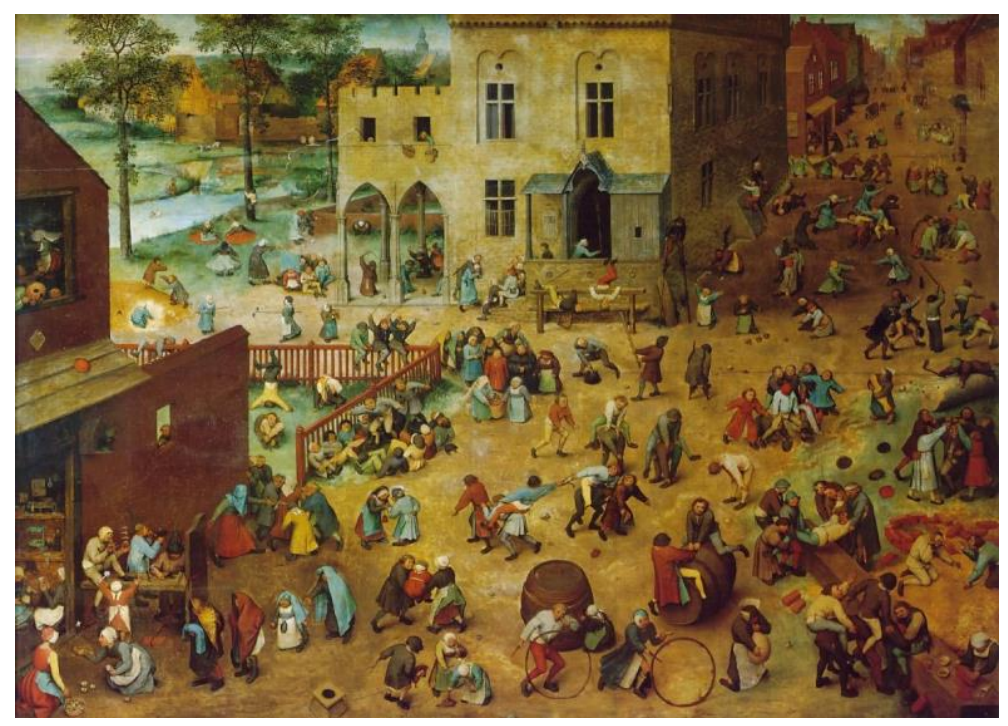

Figura 3. Pintura "jogos infantis". Fonte: Uol Brasil 500

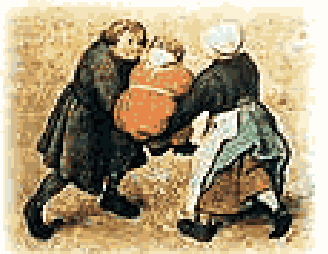

Figura 4. Maria-cadeira: fonte Uol Brasil 500

Nesta pintura podemos ver como a Cultura dos jogos, está viva a anos, porém não é algo inerente, é ensinado, e desta maneira percebemos crianças e adultos brincando juntos, trocando experiências e ensinamentos através do jogo.

Brincadeiras com regras são identificadas como jogos, segundo o dicionário Aurélio (2002), porém a brincadeira tem uma determinada ordem e organização, de modo que aqueles que fazem parte dela possam identificar relações entre outras brincadeiras parecidas ou perceber as funções e características.

Os jogos são uma forma humana de brincar que envolve a ritualização de papéis e a regulação dos cenários, possuem sequências imprevisíveis que são transformadas em ciclos com começo, meio e fim. Segundo Parker (1986 apud Ponte e Magalhães, 2002, p.218) "os jogos diferem de outras formas de brincar por requererem que ao menos um dos jogadores tenha a concepção do cenário, das regras, de suas sanções, e que o outro jogador tenha a habilidade cognitiva para seguir as regras".

Bussab (1986 apud Ponte e Magalhães, 2002,) define o brincar como uma forma de experimentar em uma situação protegida. Porém envolve também riscos, como o da perda, da

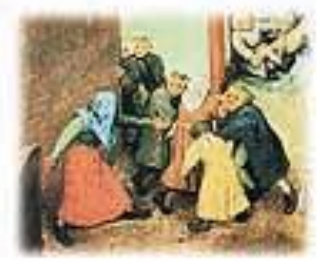

Figura 5. Cabra-cega: fonte: Uol Brasil 500

chacota e de sanções, que são necessárias para a tensão e validade da competição.

Ainda, segundo Poletto (2005, p.67), alguns autores identificam que as crianças utilizam a brincadeira como forma de resiliência, para lidar com suas dificuldades e anseios, visto que o brincar é uma atividade de apropriação cultural e uma necessidade para o bom desenvolvimento infantil.

Sobre o lugar do brincar, Lux e Kuhnen (2013) afirmam que o uso do espaço público pelas crianças foi sendo modificado ao longo do tempo por conta das mudanças sociais, econômicas e espaciais. A rua passou de lugar onde as crianças mais brincavam para um lugar perigoso.

A importância do espaço urbano para o desenvolvimento infantil é muita, porém não é tão explorada, principalmente os espaços públicos, por conta do aumento da violência, do tráfego de veículos e da falta de estrutura disponibilizada, trazendo prejuízo à saúde e à maturação infantil.

$$
\text { Os lugares planejados para as }
$$
brincadeiras foram as praças e os parques infantis, que além do papel socializador, mostravam-se importantes para o desenvolvimento infantil por oportunizar 
habilidades físicas, cognitivas, sociais e psicológicas através da atividade do brincar.

Segundo Luz e Kuhnen (2013) as crianças tem preferência por brincar em espaços que ofereçam características pessoais como idade, atributos físicos e sociais. As características e riqueza de experiências que o espaço pode oferecer podem influenciar no tipo de interação social e na intensidade de atividade realizada, demonstrando o potencial do ambiente para promover socialização, exploração, autonomia e atividade física.

Sobre o tempo do brincar infantil, considera-se que é necessário pensar que seja sinônimo de tempo da criança, sendo que na contemporaneidade podemos dizer que esse tempo está sendo sucateado para que o pequeno se transforme em um adulto bem sucedido, assim Ihe é oferecido e vivenciado aulas de música, línguas, computação, esporte, dança entre outras, atribuindo-lhes um sentido utilitarista ao seu viver.

Segundo Sarmento (2007) o tempo do adulto e da criança são diferentes. A reiteraçãoum dos eixos das culturas da infância, propostos pelo autor- é definido como o tempo da criança, ou seja, um tempo recursivo em que o brincar, principal atividade na infância, aquilo que a criança faz de mais sério é plenamente valorizado por ela.

Meira (2003 apud STAVISKI; SURDI; KUNZ, 2013) disserta que as crianças na contemporaneidade estão sendo afetadas pelo meio, ou seja, que elas passam a reproduzir no seu cotidiano, no seu brincar, o ritmo acelerado, revelando como a formação do inconsciente que se desenha nas vias da linguagem é marcada pelo social.

Como destacam Staviski, Surdi e Kunz (2013) nos últimos tempos, o brincar prazeroso, espontâneo e livre, pela lógica utilitarista já mencionada, está sendo desprezado, e a busca por resultados e uma especialização precoce vem sendo as preocupações com o futuro.

Os autores ainda propõe uma discussão sobre o tempo que vale ser destacada, e posta como fundamental para entender também qual o tempo que estamos deixando para as crianças serem de fato, crianças.

Destaca-se que desde a criação dos relógios como meio de organização da nossa vida, as pessoas tem se tornado cada vez mais proeminentes, desta forma o tempo está tão enraizado que parece se materializar a ponto de tocá-lo, falamos como se o tempo passasse, quando na verdade o que está passando é o transcorrer de nossas vidas. Os pensadores defendem então que o tempo não existe em si, mas é um símbolo social, resultado de um longo processo de aprendizagem.

Considerando essa compreensão, e o nosso ritmo acelerado de vida hoje, temos a impressão que nossa existência passa depressa demais, e o tempo já não é suficiente, porém como afirmam os autores, se os dias e os segundo continuam os mesmos, o que tem mudado é a maneira de vivermos e nos controlarmos.

Outro ponto que merece destaque nessa questão do tempo são os meios de comunicação, que mudaram, segundo Honoré (2007), as nossas vidas e nossas relações sociais. Para o sociólogo o tempo instantâneo que a internet proporciona favorece um tempo sem consequências, com realizações imediatas, de fácil acesso, e assim não há razões para passagem válidas por um longo período, o que se denomina hoje de modernidade liquida.

Por essa questão utilitarista no modo de usarmos nosso tempo, nos orientamos para a produção como se isso natural,

Maturana e Verden-Zöller (2004) alertam que, exclusivamente em nossa cultura ocidental, não fazemos apenas $o$ que fazemos, trabalhamos para alcançar um fim. Não descansamos simplesmente, nós o fazemos com o propósito de recuperar energia, não comemos simplesmente, ingerimos alimentos nutritivos, não brincamos simplesmente com nossas crianças, nós as preparamos para o futuro. 0 resultado é que, em geral, enquanto interagimos com outros seres humanos, a nossa atenção está voltada para além da interação, isto é, para as consequências, que não mais sabemos viver o momento em si; estamos perdendo a nossa sensibilidade para 0 presente de nossas vidas, e 
isto vem se constituindo como a conduta normal. (STAVISKI; SURDI; KUNZ, 2013, p.120).

Pensar somente nos resultados das atividades, só faz sentido na lógica adulta, que acaba desviando a atenção do presente, para as crianças não tem relevância alguma. As crianças não brincam pensando nos benefícios da brincadeira para o seu desenvolvimento, nem brincam de boneca para treinar quando isso lhe acontecer, elas simplesmente brincam, porque esta é sua maneira espontânea e natural de existir e estabelecer relações sociais através da brincadeira.

Muitos educadores e pais acreditam que as crianças, ao brincarem imitam atitude dos adultos, e assim compreendem que é uma excelente ferramenta para preparar o futuro, como se fosse algo biológico, somente. Porém isso é entender a brincadeira na ótica dos adultos.

A Sociologia da Infância, como uma das bases teóricas desta pesquisa, entende com Corsaro (2011) que a criança realiza uma reprodução interpretativa durante a brincadeira, ou seja, ela brinca e produz algo novo, assim elas não imitam atitudes, apenas socializam da maneira que elas entendem o mundo e isso não faz com que as prepare para o futuro, apenas entendam com melhor clareza e da sua maneira, o presente.

Os eixos das Culturas da Infância: a Fantasia do Real, a Ludicidade, a Interactividade, e principalmente a reiteração revelam que o que a criança é e sente está no seu presente. O brincar é o maior exemplo de atividade que a criança realiza que é válida e consumida em si mesmo no presente, podendo ser realizada sem objetivos concretos, mesmo que tenha propósitos, atende o nosso emocional ao fazer e não as suas consequências.

Como destacam Staviski, Surdi e Kunz (2013, p.123) a criança, por viver mergulhada no presente, vive de forma diferente os medos, pressões e conflitos do mundo social e ainda não estabelece os mesmos significados que o adulto, assim para o adulto "é difícil o esforço para se desvincular da funcionalidade da brincadeira e do tempo, enquanto para a criança, embora afetada pela sua história e pelo que os adultos esperam delas, o mundo basicamente acontece no presente".
Desta forma, concordamos ao afirmar que o brincar espontâneo, assim como o tempo e sua utilização geram influências no processo de formação das crianças, e não podem ser negligenciados e desconsiderados.

Necessário se faz destacar o trecho em que Staviski, Surdi e Kunz (2013, p. 124) destacam a organização do ensino hoje e os desafios do brincar, dando ênfase no dar voz as crianças.

Considerando a consequente influência do tempo na forma e organização do ambiente de ensino nos dias de hoje, um dos grandes desafios que os professores enfrentam é conseguir se desprender das excessivas preocupações com caráter desenvolvimentista e cognitivista, no sentido de não permitir que o fluxo criativo das atividades seja comprometido pelo tempo, ou melhor, que a atenção dos professores e das crianças não seja desviada em demasia para longe daquilo que estão fazendo e daquilo que somente pode ser feito no agora. Desta forma, tornar-se sensível para os desejos das crianças e reconhecer as suas necessidades, sem privá-las do direito de vivenciar o que querem, é uma maneira dos professores não as negarem. Em outras palavras, observar e prestar atenção ao olhar, ao tom de voz, à postura corporal, à expressão facial e corporal, à respiração ou mesmo no seu silêncio, são indícios que nos permitem aproximarmos das crianças e enxergá-las como são no presente da realização (OAKLANDER, 1980 apud STAVISKI; SURDI; KUNZ, 2013, p.124)

Os olhares, as atitudes, os gestos, são expressões capazes de apresentar emoções e 
pensamentos de uma pessoa. Acredita-se que em um momento de brincadeira proporciona uma maior interação entre pessoas e uma maior possibilidade de expressividade corporal. $\mathrm{Na}$ escola, quando ela se apresenta com uma estruturação lúdica, considera-se um ambiente rico, por proporcionar desta maneira, comportamentos naturais de forma integrada a elementos socioculturais.

Viver no presente não significa para Kunz (2004) desconsiderar radicalmente o futuro, nem viver de maneira inconsequente. Para o autor, no caso especifico de nossa área, é permitir que cada criança encontre ao seu tempo e gosto o seu potencial, é viver de maneira a respeitar e auxiliar na sua formação e no seu desenvolvimento da consciência de si mesmo.

Quando investigamos o tempo, espaço e mesmo os materiais disponíveis para brincar, percebemos que estão gradativamente comprometidos, pelo menos quando olhamos o espaço micro social, a escola. O brincar espontâneo não é valorizado como ação de uma cultura infantil necessária. Como já dito anteriormente, o brincar é apenas tolerado dede que seja declaradamente voltado para fins pedagógicos e resultados.

Infelizmente, vivências de momentos de lazer, de decisão autônoma das crianças sobre o brincar estão restritos aos horários de intervalo e recreação, assim, como indica Saura (2014), o corpo e o conhecimento de si acabam por ser colocados em um lugar secundário na relação de aprendizagem.

\section{CONCLUSÕES}

Percebemos em fim que as crianças têm a brincadeira muitas vezes sucateada, para que esse tempo dê lugar aos saberes linguísticos e matemáticos, numa antecipação da próxima fase escolar.

Entendemos que refletir sobre a questão do lugar e tempo na educação das crianças é buscar uma educação equilibrada. Cada criança tem seu tempo e lugar para viver sua infância adequadamente. Só não devemos submeter a lógica da criança pelo pensamento adultocêntrico para que sejamos de fato facilitadores de uma infância rica em experiências e não sejamos aqueles que os veem como adultos em miniatura como outrora foram (mal)compreendidos.

\section{REFERÊNCIAS}

AGOSTINHO, Kátia Adair .Pesquisa com crianças em contextos pré-escolares: reflexões metodológicas. [S.I.]: Universidade do Minho, 2007.

ANDRÉ, Marli Eliza Dalmazo Afonso. Etnografia da prática escolar. Campinas: Papirus, 2003. AURELIO: o mini dicionário da língua portuguesa. 4. ed. Rio de Janeiro: [s.n.], 2002.

BRASIL. Ministério da Educação. Conselho Nacional de Educação. Diretrizes curriculares nacionais para a educação infantil. Brasília, 2009. BROUGERE, G. Brinquedos e companhia. São Paulo: Cortez, 2006. 335 p.

CORSARO, W. A. Sociologia da Infância. Porto Alegre: Artmed, 2011.

HONORÉ, Carl. Devagar: como um movimento mundial está desafiando o culto da velocidade. Rio de Janeiro: Record, 2007.

KISHIMOTO, T. M. Jogos Infantis: o jogo, a criança e a educação. Petrópolis, Rio de Janeiro: Vozes, $12^{a}$ ed., 1993.

KUNZ, E. Didática da educação física. 2. ed. ljuí: Ed. da Unijuí, 2004. p. 15-52.

LUDKE, M.; ANDRÉ, M. E. D. A. Pesquisa em Educação: abordagens qualitativas. São Paulo: EPU, 1986.

LUZ, Giordana Machado; KUHNEN, Ariane. O uso dos espaços urbanos pelas crianças: explorando o comportamento do brincar em praças públicas. Psicol. Reflex. Crit., v. 26, n. 3, p. 552-60, 2013. https://doi.org/10.1590/S010279722013000300015 MATURANA, H.; VERDEN-ZÖLLER, G. Amar e brincar fundamentos esquecidos: fundamentos esquecidos do humano. Trad. Humberto Mariotti e Lia Diskin. São Paulo: Palas Athena, 2004.

POLETTO, R. C. A ludicidade da criança e sua regulação com o contexto familiar. Psicol. Estud. , Maringá, v.10, n.1, jan./abr. 2005 PONTES, F. A. R. ; MAGALHÃES, C. M. C. A. Estrutura da brincadeira e a regulação das relações. Psicologia: Teoria e Pesquisa, p. 213219. 2002.

RICHARDSON, R. J. Pesquisa social: métodos e técnicas. São Paulo: Atlas, 1989.

SARMENTO, M. J. Infância, exclusão social e educação como utopia realizável. Educação e Sociedade, n.78, abr. 2002. 
As culturas da Infância nas

encruzilhadas da 20 modernidade. 2003.

Disponível em

<http://cedic.iec.uminho.pt/cedic/Textos_de_Tra balho/textos/encruzilhadas.pdf>. Acesso em: 05 maio 2007.

SAURA, Soraia Chung. O imaginário do lazer e do lúdico anunciado em práticas espontâneas do corpo brincante. Revista Brasileira de Educação Física e Esporte, São Paulo, v. 1, n. 28, p.163-175, jan. 2014

STAVISKI, Gilmar; SURDI, Aguinaldo; KUNZ, Elenor. Sem tempo de ser criança: a pressa no contexto da educação de crianças e implicações nas aulas de educação física. Rev. Bras. Ciênc.

Esporte, v. 35, n. 1, p. 113-128, 2013.

UOL BRASIL 500, Disponível em

http://www1.folha.uol.com.br/fol/brasil500/brin car8.htm, Acesso em 10 de novembro de 2015.

Recebido para publicação em 19/08/2016

Revisado em 23/08/2016

Aceito em 26/09/2016 